\title{
EFEITO DA CONCENTRAÇÃO E DE FRAÇÕES OBTIDAS POR ULTRAFILTRAÇÃO DE PROTEÍNAS HIDROLISADAS SOBRE A SUPRESSÃO DO ACÚMULO DE LIPÍDEOS EM CÉLULAS PRÉ- ADIPÓCITAS
}

\author{
R. J. S. DE CASTRO ${ }^{1}$, R. F. INACIO ${ }^{2}$, A. L. R. OLIVEIRA ${ }^{2}$, H. H. SATO ${ }^{1}$ \\ ${ }^{1}$ Universidade Estadual de Campinas, Faculdade de Engenharia de Alimentos, Departamento de \\ Ciência de Alimentos \\ ${ }^{2}$ Universidade Estadual de Campinas, Instituto de Biologia, Departamento de Anatomia, Biologia \\ Celular e Fisiologia e Biofísica \\ E-mail para contato: ruannjanser@hotmail.com
}

\begin{abstract}
RESUMO - Peptídeos bioativos têm sido estudados extensivamente para elucidar seu potencial biológico e influência benéfica sobre o corpo humano. Estudos recentes relataram que frações de proteínas hidrolisadas apresentaram grande potencial quanto à capacidade de inibir processos de diferenciação celular e acúmulo de lipídeos em células adipócitas. O objetivo do presente estudo foi avaliar os efeitos da concentração e das frações de peptídeos obtidas por ultrafiltração de uma mistura binária de proteínas do soro de leite e da clara de ovo hidrolisadas com a preparação comercial de proteases Flavourzyme 500L® sobre a supressão do acúmulo relativo de lipídeos (ARL) em células pré-adipócitas 3T3-L1. Os hidrolisados proteicos foram utilizados na suplementação do meio de cultivo das células pré-adipócitas 3T3-L1 em concentrações variando de 400 a 1400ppm. Os hidrolisados foram ultrafiltrados para obtenção de três frações: I) <30 kDa, II) $<10 \mathrm{kDa}$ e III) $<3 \mathrm{kDa}$. Na avaliação do efeito da concentração dos hidrolisados, foi obtida maior porcentagem de supressão do ARL (47,93\%) quando as células 3T3-L1 foram tratadas com os hidrolisados na concentração de 1200ppm. A ultrafiltração mostrou que as frações de massas moleculares inferiores a $30 \mathrm{kDa}$ exerceram forte influência sobre a supressão do ARL.
\end{abstract}

\section{INTRODUÇÃO}

Peptídeos bioativos de proteínas alimentares têm sido estudados extensivamente ao longo da última década para elucidar seu potencial biológico e influência sobre os principais sistemas do corpo humano: digestivo, cardiovascular, nervoso e imunológico. Alguns peptídeos bioativos apresentam atividades biológicas com impacto positivo sobre a saúde, dentre as quais podemos citar: atividade antimicrobiana, antihipertensiva, antioxidante, anticancerígena, antiadipogênica e imunomoduladora, portanto têm perspectivas de serem incorporados como ingredientes em alimentos funcionais, nutracêuticos e medicamentos, onde essas bioatividades podem ser aliadas no controle e prevenção de doenças (Zhang et al., 2010; Tsou et al., 2010a; Tavares et al., 2011). 


\section{9 a 22 de outubro de 2014 \\ Florianópolis/SC}

A obesidade é resultado de um desequilíbrio entre a ingestão e a real necessidade de energia, levando a um crescimento patológico de células adipócitas (Aoyama et al., 2000). A quantidade de tecido adiposo pode ser controlada por inibição da adipogênese em células precursoras ou préadipócitas, como os pré-adipócitos 3T3-L1, que são os modelos mais bem caracterizados para o estudo de adipogênese. Muitos fatores de transcrição estão envolvidos na diferenciação de células pré-adipócitas em adipócitos, e a inibição ou regulação destes fatores pode levar a uma diminuição do acúmulo de gordura no organismo (Tsou et al., 2010a). A glicerol-3-fosfato desidrogenase (GPDH) é uma enzima que ocupa uma posição chave no metabolismo da glicose, e está ligada à biossíntese de fosfolipídeos e triglicerídeos (Harding et al., 1975, Tsou et al., 2010a). A supressão da atividade GPDH pode resultar na inibição da diferenciação bem como na redução do acúmulo de lipídeos em células 3T3-L1, assim a determinação da atividade desta enzima pode ser empregada para avaliar o efeito antiadipogênico (Hirai et al., 2005). Outra enzima envolvida no processo de adipogênese é a ácido graxo sintetase (FAS), a qual participa da síntese endógena de ácidos graxos saturados de cadeia longa a partir dos precursores acetil-CoA e malonil-CoA (Rahman et al., 2008; Maier et al., 2008). Tem sido relatado que certas frações de proteínas hidrolisadas possuem a capacidade de inibir a ação destas enzimas, regulando assim o processo de diferenciação celular e o acúmulo relativo de lipídeos. De acordo com Kim et al. (2007), estes hidrolisados apresentam grande potencial em tratamentos antiobesidade por diminuírem o acúmulo de gordura no organismo.

Uma das formas mais comuns e rentáveis de produzir peptídeos bioativos é através da hidrólise enzimática de proteínas (Hernández-Ledesma et al., 2011). Esse processo oferece algumas vantagens, como: emprego de enzimas em concentrações muito baixas, reações rápidas em condições suaves e alta especificidade, gerando um produto livre de resíduos químicos e com melhores propriedades funcionais e nutricionais (Adler-Nissen, 1981).

Neste contexto, o objetivo do presente trabalho foi avaliar a atividade antiadipogênica de uma mistura binária de proteínas do soro de leite e da clara de ovo hidrolisadas com a preparação comercial de proteases Flavourzyme 500L® durante o processo de diferenciação de células préadipócitas 3T3-L1. Estudos envolvendo a concentração mais adequada dos hidrolisados proteicos e das diferentes frações obtidas por ultrafiltração na supressão do acúmulo relativo de lipídeos foram investigados.

\section{MATERIAL E MÉTODOS}

\subsection{Protease}

A protease comercial Flavourzyme ${ }^{\circledR}$ 500L de Aspergillus oryzae (Novozymes e comercializada pela Sigma Aldrich) foi utilizada para obtenção dos hidrolisados proteicos.

\subsection{Obtenção dos hidrolisados proteicos}

Para obtenção dos hidrolisados proteicos, foi utilizada uma mistura binária de proteínas do soro de leite e proteínas da clara de ovo em iguais proporções. Amostras de $50 \mathrm{~mL}$ das soluções de proteínas $10,0 \%(\mathrm{p} / \mathrm{v})$ e protease Flavourzyme 500L (50 U por $\mathrm{mL}$ de mistura reacional) foram 


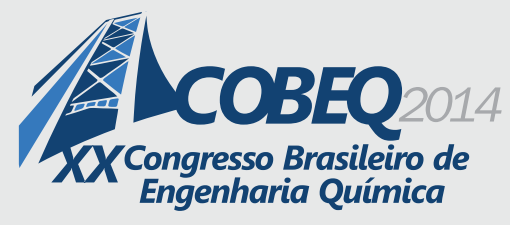

19 a 22 de outubro de 2014
Florianópolis/SC

incubadas em pH 5,0 em banho-maria a 50 ${ }^{\circ} \mathrm{C}$ sob agitação de $100 \mathrm{rpm}$ durante $2 \mathrm{~h}$. Após a hidrólise, as soluções foram submetidas a tratamento térmico $\left(100^{\circ} \mathrm{C}\right.$ por $\left.20 \mathrm{~min}\right)$ para inativação das proteases. As amostras foram centrifugadas a $17.000 \mathrm{x} \mathrm{g}$ a $5^{\circ} \mathrm{C}$ por $20 \mathrm{~min}$ e os sobrenadantes contendo os peptídeos bioativos foram coletados, congelados e liofilizados para os estudos de supressão do acúmulo relativo de lipídeos em células pré-adipócitas 3T3-L1.

\subsection{Inibição do acúmulo relativo de lipídeos em células 3T3-L1: efeito anti-adipogênico}

Cultivo das células e tratamento com os hidrolisados: As análises foram realizadas no Laboratório de Regeneração Nervosa, Departamento de Anatomia, Biologia Celular e Fisiologia e Biofísica do Instituto de Biologia da Universidade Estadual de Campinas. Para verificação do efeito anti-adipogênico dos hidrolisados proteicos foi utilizada cultura de células 3T3-L1 (pré-adipócitos), proveniente do Banco de Células do Rio de Janeiro da Universidade Federal do Rio de Janeiro. As células pré-adipócitas 3T3-L1 foram semeadas em uma placa de 24 poços a uma densidade de $10^{3}$ células/poço. As células foram cultivadas em DMEM (Dulbecco's Modified Eagle Medium) suplementado com $10 \%$ de soro fetal bovino a $37^{\circ} \mathrm{C}$ em estufa com atmosfera de $\mathrm{CO}_{2}(5,0 \%)$. Para indução da diferenciação, após $48 \mathrm{~h}$ de cultivo e atingida a confluência, as células pré-adipócitas 3T3L1 foram estimuladas durante 48 horas com 3-isobutil-1-metilxantina $(0,5 \mathrm{mM})$, dexametasona $(0,1 \mu \mathrm{M})$ e insulina $(10 \mu \mathrm{g} / \mathrm{mL}$ em DMEM suplementado com soro fetal bovino (10,0\%) (fase de diferenciação). Em seguida, as células pré-adipócitas foram mantidas com aplicação de meio DMEM suplementado com soro fetal bovino $(10,0 \%)$ e $10 \mu \mathrm{g}$ de insulina/mL a cada $48 \mathrm{~h}$ durante 6 dias. O efeito anti-adipogênico dos hidrolisados foi avaliado segundo a supressão do acúmulo relativo de lipídeos (RLA) (Green e Kehinde, 1975) nas células 3T3-L1. O tratamento consistiu na aplicação dos hidrolisados proteicos durante o início da fase de diferenciação (2 dias pós confluência) e a cada 2 dias, até ao final dos experimentos no $8^{\circ}$ dia. Para verificação da influência dos peptídeos provenientes da preparação enzimática de proteases, testes preliminares foram realizados, onde as células pré-adipócitas 3T3-L1 foram tratadas com a preparação enzimática na mesma concentração utilizada para obtenção dos hidrolisados proteicos $\left(50 \mathrm{U} \mathrm{mL}^{-1}\right)$ previamente inativada em banho em ebulição por 20 min.

Determinação do acúmulo relativo de lipídeos (ARL) em células 3T3-L1: No $6^{\circ}$ dia após a diferenciação ( $8^{\circ}$ dia de tratamento), as células 3T3-L1 foram coradas com Oil Red para determinação do conteúdo de lipídeos intracelulares ou de triglicerídeos (Green e Kehinde, 1975). As células foram fixadas com formaldeído $(10,0 \%)$ durante $1 \mathrm{~h}$ a temperatura ambiente. Após a fixação, as células foram lavadas duas vezes com isopropanol $(60,0 \%)$ e corada com uma solução de Oil Red $(0,3 \%) \mathrm{em}$ isopropanol durante 15 min a temperatura ambiente. A solução de Oil Red foi removida e os poços lavados quatro vezes com água destilada. Após a lavagem, adicionou-se 1,5mL de isopropanol $(100,0 \%)$ para dissolução completa do complexo contendo os lipídeos intracelulares, triglicerídeos e o Oil Red. A absorbância do complexo medida a 540nm é proporcional à concentração de lipídeos presente em cada amostra. O ARL (\%) foi expresso como a relação entre a absorbância da cultura de células tratadas com os hidrolisados proteicos e culturas controle (onde os hidrolisados não foram aplicados). 
Efeito da concentração dos hidrolisados proteicos sobre o acúmulo relativo de lipídeos (ARL): A mistura binária contendo proteínas do soro de leite e da clara de ovo hidrolisados foi avaliada em concentrações variando de 400 a 1400 ppm.

Fracionamento dos hidrolisados por ultrafiltração: A amostra hidrolisada contendo a mistura binária de proteínas do soro de leite e da clara de ovo, na concentração mais adequada para supressão do ARL, foi submetida à ultrafiltração. $O$ fracionamento foi realizado utilizando tubos de centrífuga para ultrafiltração com membranas de corte (MWCO) de massas moleculares de 30, 10 e 3 kDa (Millipore Corporation ${ }^{\circledR}$ membranas de ultrafiltração, Billerica, EUA).

\section{RESULTADOS E DISCUSSÃO}

Os resultados obtidos mostraram que as células pré-adipócitas 3T3-L1 tratadas com a preparação de proteases previamente inativada não apresentaram diferenças significativas quando comparados aos ensaios onde as células não foram tratadas, portanto, os peptídeos gerados pela presença da enzima não apresentaram influência sobre a supressão do ARL (dados não apresentados).

O aumento na concentração das amostras de hidrolisados contendo a mistura binária de proteínas do soro de leite e da clara de ovo aumentou a supressão do ARL nas células 3T3-L1, alcançando níveis máximos de supressão de 47,93\% na concentração de 1200ppm (Figura 1).

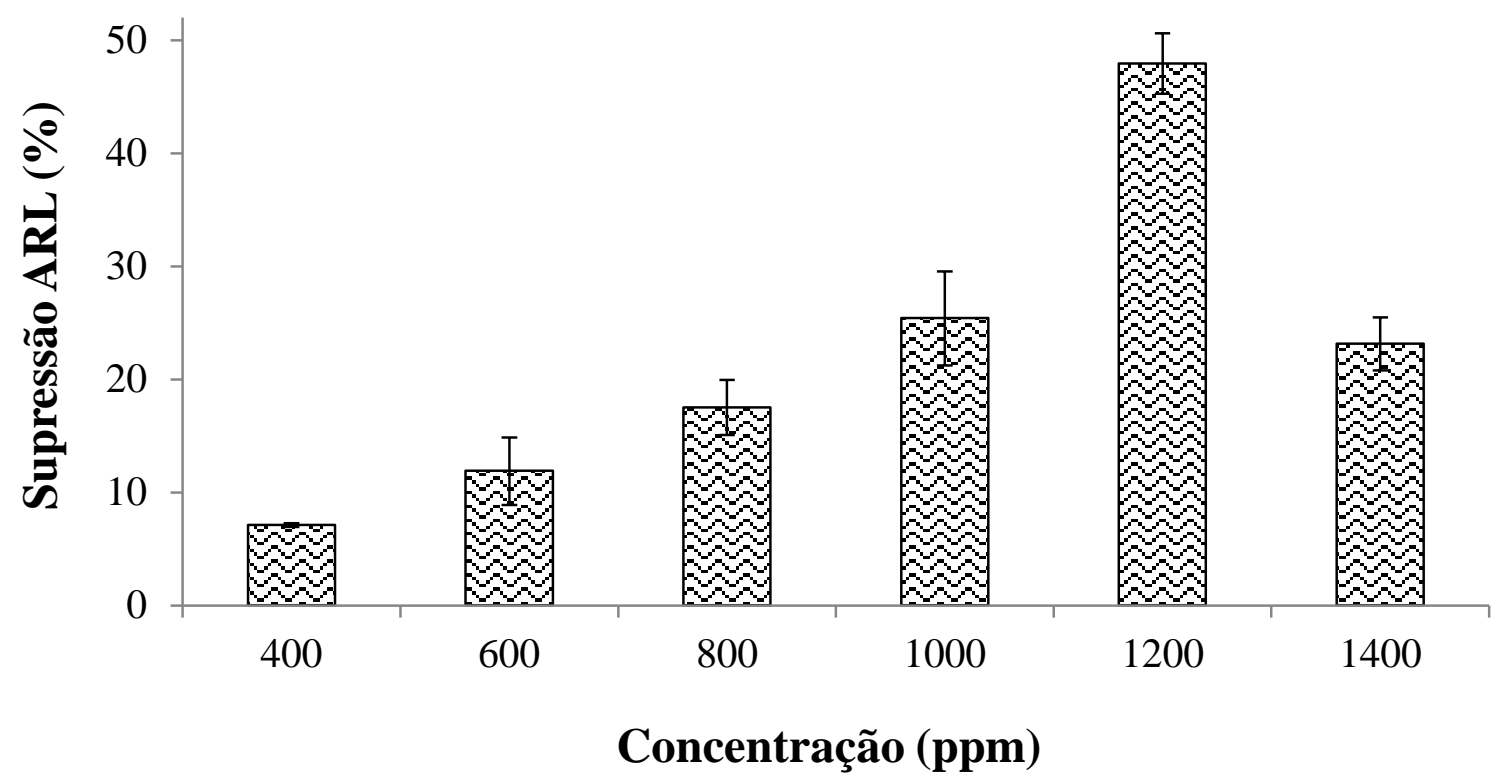

Figura 1 - Efeito da concentração da mistura binária de proteínas do soro de leite (1/2) e da clara de ovo (1/2) hidrolisadas sobre a supressão do ARL (\%) em células pré-adipócitas 3T3-L1

durante diferenciação. 


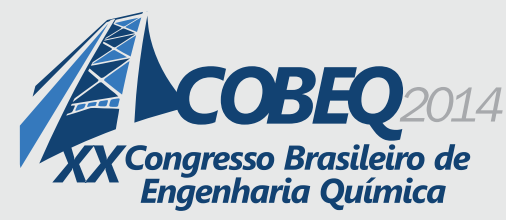

19 a 22 de outubro de 2014

Florianópolis/SC

Os hidrolisados da mistura binária contendo proteínas do soro de leite e da clara de ovo foram ultrafiltrados para obtenção de três frações: I) permeado $30 \mathrm{kDa}(<30 \mathrm{kDa})$, II) permeado $10 \mathrm{kDa}(<10 \mathrm{kDa})$ e III) permeado $3 \mathrm{kDa}(<3 \mathrm{kDa})$. Os valores de ARL $(\%)$ nas células préadipócitas 3T3-L1 tratadas com as frações ultrafiltradas foram avaliados comparativamente com os resultados obtidos para os tratamentos realizados com os hidrolisados não fracionados e ao controle, onde não houve tratamento (100,0\% de ARL). Verificou-se que as células 3T3-L1 apresentaram ARL entre 52,07 e 83,75\%, resultando em supressão máxima de 47,93\% quando tratadas com a amostra não fracionada (Figura 2). Os valores de ARL (\%) obtidos nos tratamentos com as frações ultrafiltradas mostraram que há uma forte contribuição dos peptídeos de massas moleculares inferiores a $30 \mathrm{kDa}$ sobre a supressão do acúmulo relativo de lipídeos nas células 3T3-L1 (Figura 2). É válido ressaltar, que estes resultados indicaram que a hidrólise enzimática com a protease comercial Flavourzyme 500L resultou em hidrolisados com distribuição equilibrada de tamanho de peptídeos e alta atividade antiadipogênica. Assim, o uso de ultrafiltração como um passo subsequente para obtenção de frações concentradas torna-se opcional, sendo um aspecto positivo para o processo. É válido ressaltar que a atividade biológica de proteínas e de seus hidrolisados está fortemente ligada à sequência e presença de aminoácidos específicos, não restringindo assim, a supressão do ARL nas células pré-adipócitas 3T3-L1 somente ao tamanho dos peptídeos presentes em cada fração.

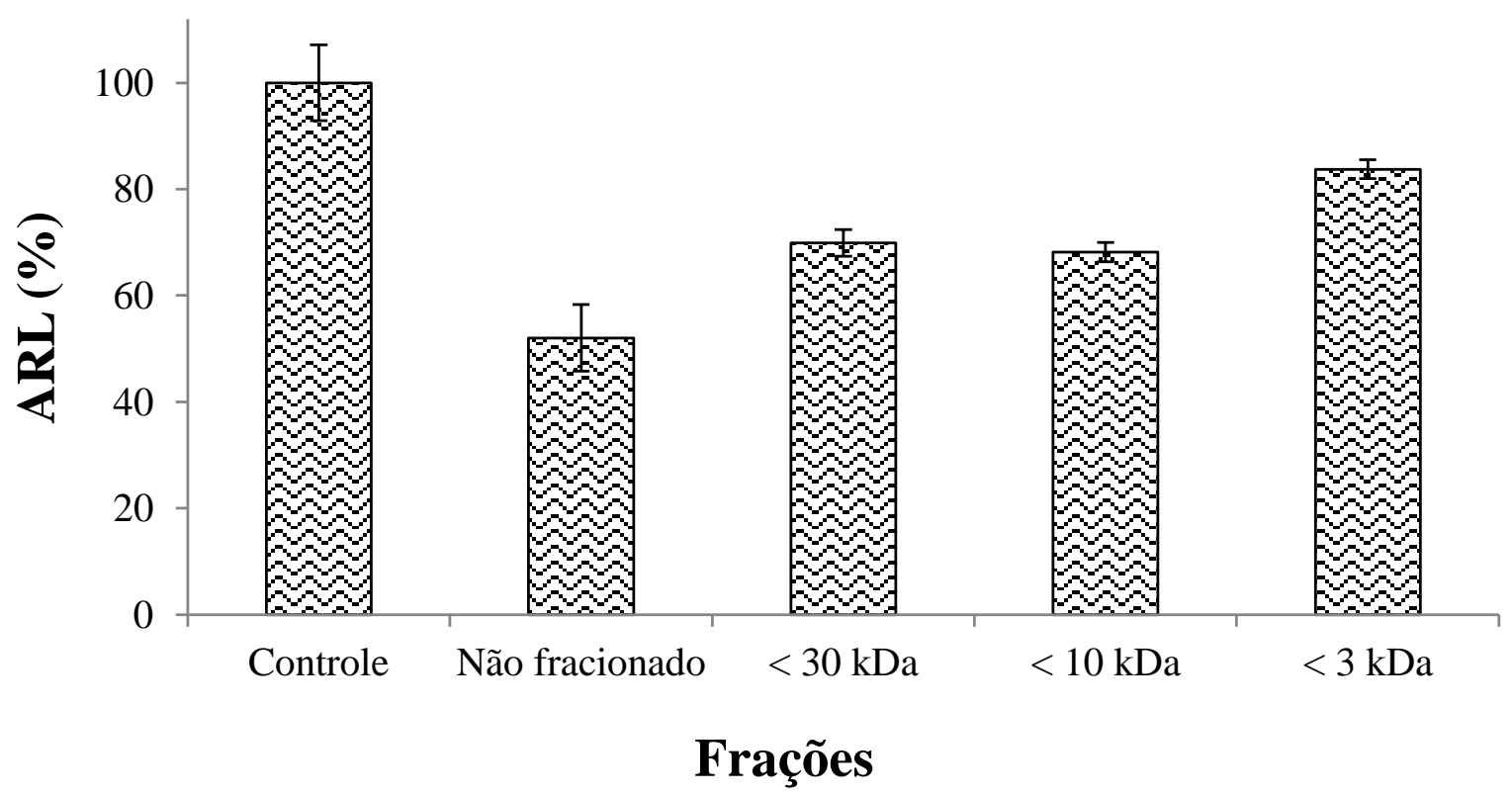

Figura 2 - ARL (\%) para as células pré-adipócitas 3T3-L1 tratadas com diferentes frações dos hidrolisados de proteínas do soro de leite e da clara de ovo obtidas após ultrafiltração. 


\section{9 a 22 de outubro de 2014 \\ Florianópolis/SC}

A ultrafiltração pode ser utilizada para refinar, fracionar e obter peptídeos de forma mais concentrada e em tamanhos selecionados, no entanto há relatos que reportam aumento ou diminuição de atividades biológicas nas frações obtidas. Picot et al. (2010) estudaram a aplicação de ultrafiltração e nanofiltração com o intuito de verificar o impacto sobre a estabilidade e atividades biológicas de peptídeos bioativos obtidos por hidrólise enzimática de proteína de peixe. Os resultados obtidos mostraram que o fracionamento não gerou aumento ou até mesmo diminuíram as atividades antioxidante e anti-hipertensiva. Bernardini et al. (2012) estudaram o impacto do fracionamento por ultrafiltração de hidrolisados de proteínas sarcoplasmáticas de carne bovina obtidos por hidrólise com papaína. Foi observado que a capacidade de quelar $\mathrm{Fe}^{2+}$ (atividade antioxidante) aumentou significativamente na fração obtida por UF em membranas de 10 kDa. Gómez-Guillén et al. (2010) mostraram que a atividade antioxidante de hidrolisados de gelatina aumentou até $62 \%$ quando fracionados em membranas de $1 \mathrm{kDa}$. Tsou et al. (2010a) estudaram a aplicação de uma preparação comercial de proteases (Flavourzyme) na obtenção de hidrolisados proteicos de soja e avaliaram a capacidade antiadipogênica de frações dos hidrolisados submetidos a ultrafiltração. Os resultados obtidos revelaram que a hidrólise limitada de proteína isolada de soja permitiu a obtenção de hidrolisados com grande capacidade antiadipogênica, e que as frações obtidas por ultrafiltração inibiram mais eficientemente a atividade de glicerol-3-fosfato desidrogenase GPDH, sendo a fração obtida com membranas de 1 $\mathrm{kDa}$, a mais efetiva (59\% de inibição). Tsou et al. (2010b) estudaram o efeito antiadipogênico de hidrolisados de proteína isolada de soja após tratamento enzimático com Neutrase e o efeito do fracionamento por ultrafiltração sobre a bioatividade. Assim como no estudo anterior, os resultados mostraram que peptídeos com massa molecular reduzida (entre 1300 e 2200 Da) foram mais efetivos na inibição da atividade GPDH.

\section{CONCLUSÃO}

Os resultados obtidos mostraram que a hidrólise enzimática utilizando a preparação comercial de proteases Flavourzyme ${ }^{\circledR}$ 500L e uma mistura binária contendo proteínas do soro de leite e da clara de ovo, apresentou influência positiva sobre a supressão do acúmulo relativo de lipídeos em células pré-adipócitas 3T3-L1 durante a diferenciação. O maior nível de supressão do ARL (\%) foi de 47,93\% quando as células 3T3-L1 foram tratadas com a mistura de proteínas do soro de leite e da clara de ovo hidrolisadas na concentração de $1200 \mathrm{ppm}$. A ultrafiltração mostrou que frações de massas moleculares inferiores a $30 \mathrm{kDa}$ exerceram forte influência sobre a supressão do ARL. 


\section{REFERÊNCIAS}

ADLER-NISSEN, J. Procesamiento enzimático de las proteínas alimenticias. Alimentos, v. 6, p. 29-33, 1981.

AOYAMA, T., FUKUI, K., TAKAMATSU, K., HASHIMOTO, Y., YAMAMOTO, T. Soy protein isolate and its hydrolysate reduce body fat of dietary obese rats and genetically obese mice (yellow KK). Nutrition, v. 16, p. 349-354, 2000.

BERNARDiNI, R. D., MULLEN, A. M., BOLTON, D., KERRY, J., O'NEILL, E., HAYES, M. Assessment of the angiotensin-I-converting enzyme (ACE-I) inhibitory and antioxidant activities of hydrolysates of bovine brisket sarcoplasmic proteins produced by papain and characterisation of associated bioactive peptidic fractions. Meat Science, v. 90, p. 226-235, 2012.

GÓMEZ-GUILLÉN, M. C., LÓPEZ-CABALLERO, M. E., LÓPEZ DE LACEY, A., ALEMÁN, A., GIMÉNEZ, B., MONTERO, P. Antioxidant and antimicrobial peptide fractions from squid and tuna skin gelatin. In Bihan, E. L., Koueta, N. Sea by-products as a real material: new ways of application. Kerala: Transworld Research Network Signpost, 2010. p. 89-115.

GREEN, H., KEHINDE, O. An established preadipose cell line and its differentiation in culture. II. Factors affecting the adipose conversion. Cell, v. 5, p. 19-27, 1975.

HARDING, J. W., PYERITZ, E. A., COPELAND, E. S., WHITE, H. B. Role of glycerol 3phosphate dehydrogenase in glyceride metabolism. Effect of diet on enzyme activities in chicken liver. Biochemistry Journal, v. 146, p. 223-229, 1975.

HERNÁNDEZ-LEDESMA, B., CONTRERAS, M. M., RECIO, I. Antihypertensive peptides: Production, bioavailability and incorporation into foods. Advances in Colloid and Interface Science, v. 165, p. 23-35, 2011.

HIRAI, S., YAMANAKA, M., KAWACHI, H., MATSUI, T., YANO, H. Activin A inhibits differentiation of 3T3-L1 preadipocyte. Molecular and Cellular Endocrinology, v. 232, p. 21-26, 2005.

KIM, H. J., BAE, I. Y., AHN, C., LEE, S., LEE, H. G. Purification and identification of adipogenesis inhibitory peptide from black soybean protein hydrolysate. Peptides, v. 28, p. 20982103, 2007.

MAIER, T., LEIBUNDGUT, M., BAN, N. The crystal structure of mammalian fatty acid synthase. Science, v. 321, p. 1315-1322, 2008.

PICOT, L. RAVALLEC, R., FOUCHEREAU-PÉRON, M., VANDANJON, L., JAOUEN, P., CHAPLAIN-DEROUINIOT, M., GUÉRARD, F., CHABEAUD, A., LEGAL, Y., ALVAREZ, O. M., BERGÉ, J. P., PIOT, J. M., BATISTA, I., PIRES, C., THORKELSSON, G., DELANNOY, C., JAKOBSEN, G., JOHANSSON, I., BOURSEAU, P. Impact of ultrafiltration 
and nanofiltration of an industrial fish protein hydrolysate on its bioactive properties. Journal of the Science of Food and Agriculture, v. 90, 1819-1826, 2010.

RAHMAN, M. A., KUMAR, S. G., KIM, S. W., HWANG, H. J., BAEK, Y. M., LEE, S. H., HWANG, H. S., SHON, Y. H., NAM, K. S., YUN, J. W. Proteomic analysis for inhibitory effect of chitosan oligosaccharides on 3T3-L1 adipocyte differentiation. Proteomics, v. 8, p. 569-581, 2008.

TAVARES, T. G., CONTRERAS, M. M., AMORIM, M., MARTÍN-ÁLVAREZ, P. J., PINTADO, M. E., RECIO, I., MALCATA, F. X. Optimisation, by response surface methodology, of degree of hydrolysis and antioxidant and ACE-inhibitory activities of whey protein hydrolysates obtained with cardoon extract. International Dairy Journal, v. 21, p. 926933, 2011.

TSOU, M. J., KAO, F. J., TSENG, C. K., CHIANG, W. D. Enhancing the anti-adipogenic activity of soy protein by limited hydrolysis with Flavourzyme and ultrafiltration. Food Chemistry, v. 122, p. 243-248, 2010a.

TSOU, M., LIN, W., LU, H., TSUI, Y., CHIANG, W. The effect of limited hydrolysis with Neutrase and ultrafiltration on the anti-adipogenic activity of soy protein. Process Biochemistry, v. 45, p. 217-222, 2010 b.

ZHANG, L., LI, J., ZHOU, K. Chelating and radical scavenging activities of soy protein hydrolysates prepared from microbial proteases and their effect on meat lipid peroxidation. Bioresource Technology, v. 101, p. 2084-2089, 2010. 